\title{
Analytical methods in strigolactone research
}

\author{
Rostislav Halouzka ${ }^{1}$, Sanja Ćavar Zeljković ${ }^{1,2}$, Bořivoj Klejdus ${ }^{3,4}$ and Petr Tarkowski ${ }^{1,2^{*}}$ (D)
}

\begin{abstract}
Strigolactones (SLs) are important plant hormones that are produced via the carotenoid biosynthetic pathway and occur at extremely low concentrations in various plant species. They regulate root development, play important roles in symbioses between higher plants and mycorrhizal fungi, and stimulate germination of plant-parasitic Orobanche and Striga species. Chemical analysis is central to research on the biochemistry of SLs and their roles in developmental biology and plant physiology. Here we summarize key issues relating to the identification and quantification of SLS isolated from plant tissues and exudates. The advantages and drawbacks of different protocols used for strigolactone analysis are discussed, and guidelines for selecting a procedure that will minimize losses during isolation and purification prior to final analysis are proposed. Hyphenated techniques suitable for SL analysis such as GC-MS and LC-MS/ MS are also discussed, and newer ambient techniques such as HR-DART-MS and DESI-MS are highlighted as tools with considerable potential in SL research. A key advantage of these methods is that they require only simply sample preparation.
\end{abstract}

Keywords: Strigolactones, Isolation, Determination, GC-MS, LC-MS/MS, HR-DART-MS, DESI-MS

\section{Background}

Strigolactones (SLs) are a poorly characterized group of plant hormones [1], although they have been known for over 60 years because of their interactions with parasitic weeds such as Orobanche, Striga and Phelipanche. They occur in diverse plant species, ranging from mosses to higher plants such as Pinus sp. and Eucalyptus sp. [2-5]. The first SLs to be described were strigol and its acetate, both of which were isolated from cotton and named after the plant genus Striga, which is parasitic on cotton $[2,6]$.

As plant hormones, SLs regulate developmental processes including the induction of secondary growth, acceleration of leaf senescence, stimulation of internode growth, and root elongation. They also inhibit axillary bud outgrowth and the formation of adventitious and lateral roots [7]. Additionally, SLs serve as signaling molecules with important roles in the induction of hyphal

\footnotetext{
*Correspondence: petr.tarkowski@upol.cz; tarkowski@genobanka.cz ${ }^{1}$ Centre of Region Haná for Biotechnological and Agricultural Research, Department of Phytochemistry, Faculty of Science, Palacky University, Šlechtitelů 27, 78371 Olomouc, Czechia

Full list of author information is available at the end of the article
}

branching in arbuscular mycorrhiza (AM) and stimulating seed germination in parasitic plants $[1,8]$. Recent findings indicate variation in the biological activity of SLs. For instance, orobanchol is highly active towards AM fungi but is a weaker stimulator of parasitic seed germination in Striga hermonthica than its biosynthetic precursor ent-2'-epi-5-deoxystrigol [9].

SL biosynthesis occurs primarily in the roots [3], from where SLs are either secreted into the rhizosphere or transported to the shoots [10-12]. They are synthesized via the carotenoid biosynthetic pathway [1]. In structural terms, SLs consist of a tricyclic lactone (ABC moiety) and a methylated butenolide (ring D) coupled via an enol ether linkage. The enol ether is unstable and easily cleaved or hydrolysed even under mild conditions [13]. Ring D is a characteristic feature of all naturally occurring SLs (Fig. 1), [14]. Minor modifications of the ABC moiety such as methylation, acetylation, or hydroxylation influence the compound's biological activity. Enzymatic hydroxylation can occur on the $\mathrm{AB}$ rings; hydroxylation at the $\mathrm{C}-4, \mathrm{C}-5$, and $\mathrm{C}-9$ positions results in the formation of orobanchol, strigol, and sorgomol, respectively. Conversely, no SLs hydroxylated on the C or D rings have

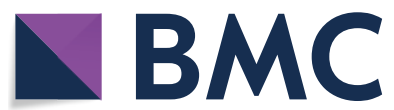

(c) The Author(s) 2020. This article is licensed under a Creative Commons Attribution 4.0 International License, which permits use, sharing, adaptation, distribution and reproduction in any medium or format, as long as you give appropriate credit to the original author(s) and the source, provide a link to the Creative Commons licence, and indicate if changes were made. The images or other third party material in this article are included in the article's Creative Commons licence, unless indicated otherwise in a credit line to the material. If material is not included in the article's Creative Commons licence and your intended use is not permitted by statutory regulation or exceeds the permitted use, you will need to obtain permission directly from the copyright holder. To view a copy of this licence, visit http://creativeco mmons.org/licenses/by/4.0/. The Creative Commons Public Domain Dedication waiver (http://creativecommons.org/publicdomain/ zero/1.0/) applies to the data made available in this article, unless otherwise stated in a credit line to the data. 


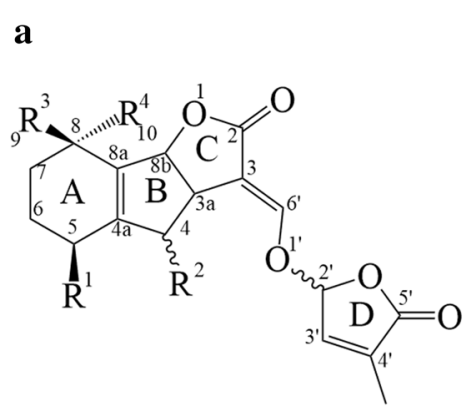

d<smiles>CC1=C[C@H](O/C=C(C)\C=C\C2=C(C)CCCC2(C)C)OC1=O</smiles>

b<smiles>CC1=C[C@H](O/C=C2/C(=O)O[C@@H]3C4=C(CC23)[C@H](O)CCC4(C)C)OC1=O</smiles>

e

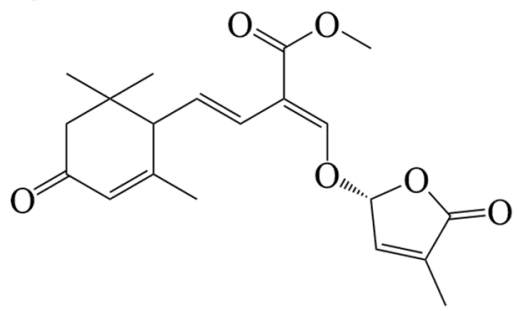

c<smiles>CC1=C[C@H](O/C=C2/C(=O)O[C@H]3C4=C(CCCC4(C)C)[C@H](O)C23)OC1=O</smiles>

f<smiles>CC1=C[C@H](O/C=C2/C(=O)OC3c4ccccc4CC23)OC1=O</smiles>

Fig. 1 Chemical structures of selected strigolactones. a General structure; b (+)-Strigol; c (+)-Orobanchol; d Carlactone; e Heliolactone; f Synthetic SL analogue (GR24)

yet been reported $[9,15]$; such structures would be quite unstable. There are also non-canonical SLs such as heliolactone (Fig. 1e) from sunflowers [16] and lotuslactone from Lotus japonicus [17]. These compounds lack the A-, $\mathrm{B}-$, or $\mathrm{C}$ - ring but retain the enol-ether-D ring moiety, which is essential for the biological activities of SLs.

Chemical analysis of small molecules, including plant hormones, is central to studies on plant development and host-microbe interactions. In particular, information on hormone levels is essential for researchers working on any kind of hormone-regulated process. The analysis of phytohormones such as strigolactones is very challenging because the endogenous concentration of the target molecules in plant tissues are often very low (on the order of $\mathrm{pg} / \mathrm{g}$ fresh weight), so the presence of much more abundant compounds can cause significant interference. These problems can be particularly severe if the interfering compounds have similar structures and/or physicochemical properties to the target analytes. Other factors that complicate hormonal analysis include the high complexity of plant matrices and the limited chemical, light, and thermal stability of many target compounds [18-20]. Proper purification is necessary to obtain reliable data, and simplification of purification protocols often intensifies matrix effects, making final analysis very difficult or even impracticable [21, 22]. The most popular technique for final analysis of phytohormones over the last decade has been liquid chromatography-tandem mass spectrometry, which combines a high-resolution chromatographic system with sensitive and acceptably selective mass spectrometric detection [20].

This review summarizes the advantages and disadvantages of isolating SLs from root tissue and exudates, presents noteworthy findings related to their qualitative and quantitative chemical analysis, and offers some future perspectives on research in this area.

\section{Isolation and purification}

Sample preparation is an essential step in any chemical analysis of plant metabolites, especially phytohormones. SLs occur mainly in root exudates and root tissues [11, 23] but the SL profiles of root exudates and roots differ, probably because of the different biological roles of individual compounds. Their isolation from root exudates is limited by the presence of inorganic salts in the medium. Extracts containing such salts are incompatible with the chromatographic methods used for final analyses due to their harmful effects on the detectors. In addition, extraction requires the processing of relatively large volumes of media (typically litres). Therefore, the capacity of the solvent and/or sorbent used must be carefully considered when analyzing root exudates.

Conversely, isolating and purifying SLs from root tissues requires pre-concentration of the target compounds, sample desalting, and also removal of interfering substances. In this case, the main unwanted contaminants 
are organic compounds with physicochemical properties similar to the target analytes.

SLs are produced in very low quantities, on the order of $15-30 \mathrm{pg} / \mathrm{plant} /$ day $[18,24,25]$. It is therefore essential to minimize losses during isolation and purification in order to maximize recovery of the target compounds over the sample preparation process. Isolating SLs from plants is very laborious, and it is generally impossible to guarantee that the quantities obtained will be sufficient to determine the structure of previously uncharacterized SLs $[14,18]$. The first SL isolation procedures required over 25,000 plants, but the use of modern chromatographic and spectrometric methods has significantly reduced the number of plants needed [26, 27]. Over the last two decades, the quantity of plant material required for SL profiling has fallen from tens of kilograms (e.g. Yokota et al. [27]) to grams or even milligrams (e.g. Charnikova et al. [28] or Rial et al. [29]), mainly because of advances in instrumentation, but also because of more efficient sample isolation and purification procedures.

The most common procedures for SL isolation from root exudates are based on adsorption on charcoal [3032]. Many rather similar protocols for isolating and purifying SLs from root tissue have been presented [11, 33, 34]; that developed by Yoneyama et al. [34] is generally accepted as the standard protocol, but was recently modified by Boutet-Mercey et al. [35]. They ground the plant material before extraction, while Yoneyama et al. [34] extracted intact plant tissue. In addition, Boutet-Mercey et al. [35] purified the extract via SPE. More details and the differences between these two approaches are described in the following section.

\section{Isolation of SLs from root exudates}

Plant exudates are complex mixtures of bioactive phytochemicals containing both low- and high-molecular weight compounds that are important for plant adaptation and defence [36, 37]. Exudates are generally secreted by plant root hairs, calli, and suspension cells [36]. The collection of exuded bioactive phytochemicals is a non-destructive process that can be repeated several times to obtain higher quantities of the desired molecules [38, 39]. Plant seedlings for SL production are usually grown in hydroponic culture systems. In these systems, seeds are sterilized and germinated, then once the seedlings are 2 days old, they are transferred into a strainer with a sheet of gauze linked to a slightly larger container containing various volumes of tap water or nutrient solution [40, 41]. Tap water can typically be used as the medium for the first 3-5 days to acclimatize the plants, after which a growth medium containing nutrients is applied. The medium can be used throughout the cultivation process, and because
SL production and exudation are sensitive to nutrient availability [40-43], the cultivation timeframe can be tuned. Three different types of cultivation media are widely used today: most European groups use Hoagland medium, but Japanese researchers prefer Tadano and Tanaka medium or a modified Long Ashton nutrient solution $[28,44,45]$. These cultivation media contain various inorganic salts, which may bind to target compounds. For instance, higher concentrations of phosphate $(\geq 5 \mathrm{mM})$ in the cultivation media negatively affect both the production and stability of SLs in root exudates. Rial et al. [29] analyzed both exudates and root tissues from tomato plants grown under $-\mathrm{P}$ and $+\mathrm{P}$ conditions, and observed significantly lower SL concentrations in samples grown under $+\mathrm{P}$ conditions. We found that phosphate and some other nucleophiles promoted the degradation of the SL synthetic analog, GR24 [13]. Phosphate is a good example of an inorganic ion influencing both SL biosynthesis in plants and their stability in aqueous solutions.

There are two common approaches for collection/ extraction of SLs from root exudates: (A) combined collection with charcoal followed by SPE (solid phase extraction) and (B) direct LLE (liquid/liquid extraction) of target compounds from the media [23, 30, 40, 43] (Table 1). Combined collection yields relatively low recoveries-typically, $>20 \%$ (Halouzka, unpublished results)-and the selectivity of adsorption on charcoal is limited by the large quantities of hydroponic solution that must be passed through the sorbent. Adsorbed root exudates are eluted with acetone, evaporated to dryness, re-dissolved in water, and then extracted with ethyl acetate (EtOAc) via LLE [30]. EtOAc is the preferred extraction solvent for SLs due to its moderate polarity and low toxicity. However, the use of freshly distilled solvent is strongly recommended because residual acetic acid degradates SLs. The EtOAc extracts are then washed with $0.2 \mathrm{M} \mathrm{K}_{2} \mathrm{HPO}_{4}(\mathrm{pH}$ 8.3) to obtain a neutral fraction. Finally, the extract is dried over anhydrous $\mathrm{MgSO}_{4}$ or $\mathrm{NaSO}_{4}$ and concentrated in vacuo [40,43].

The LLE approach involves directly extracting SLs from the cultivation media without prior adsorption on a sorbent. The collected root exudates are extracted repeatedly with an equal volume of EtOAc [43], then the extracts are combined and neutralized (Fig. 2B). Collection and extraction are repeatable processes that can be performed over several days [31]. Most SLs characterized to date were isolated from root exudates [18, 28, 30, 32, 33].

A third way of isolating SLs from exudates was presented by Rial et al. [29], who analyzed concentrated exudates without pretreatment after dissolution in $\mathrm{MeOH}$. This resulted in successful quantification even though the nucleophilicity of $\mathrm{MeOH}$ makes it a suboptimal 


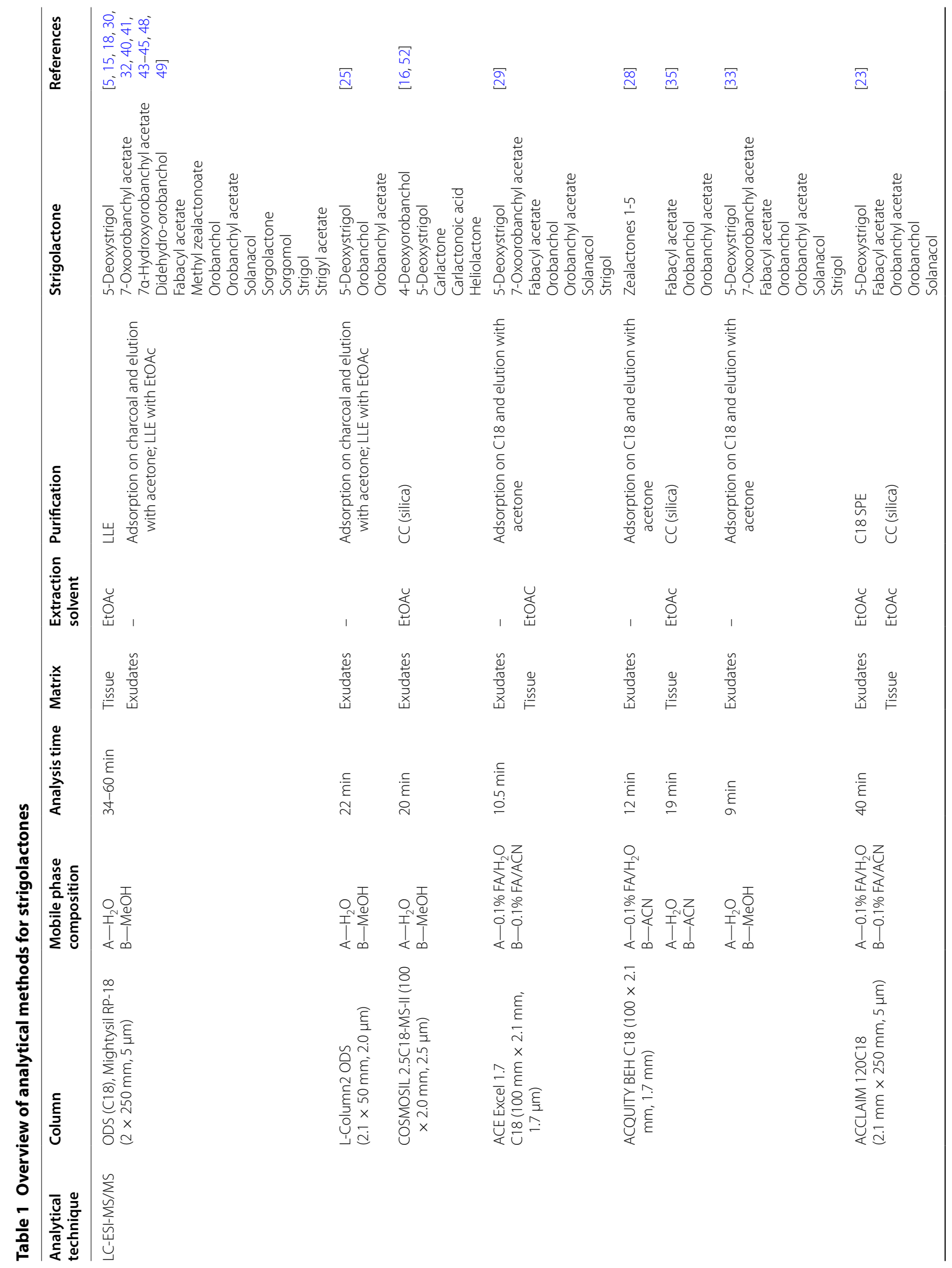




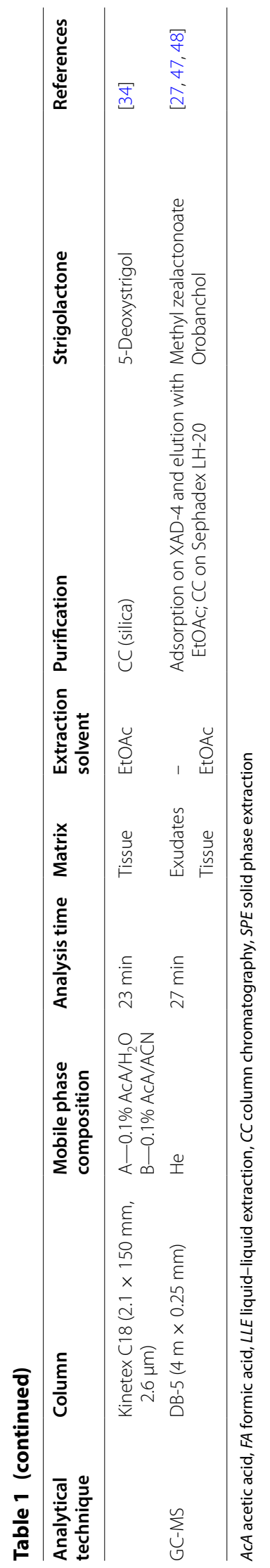




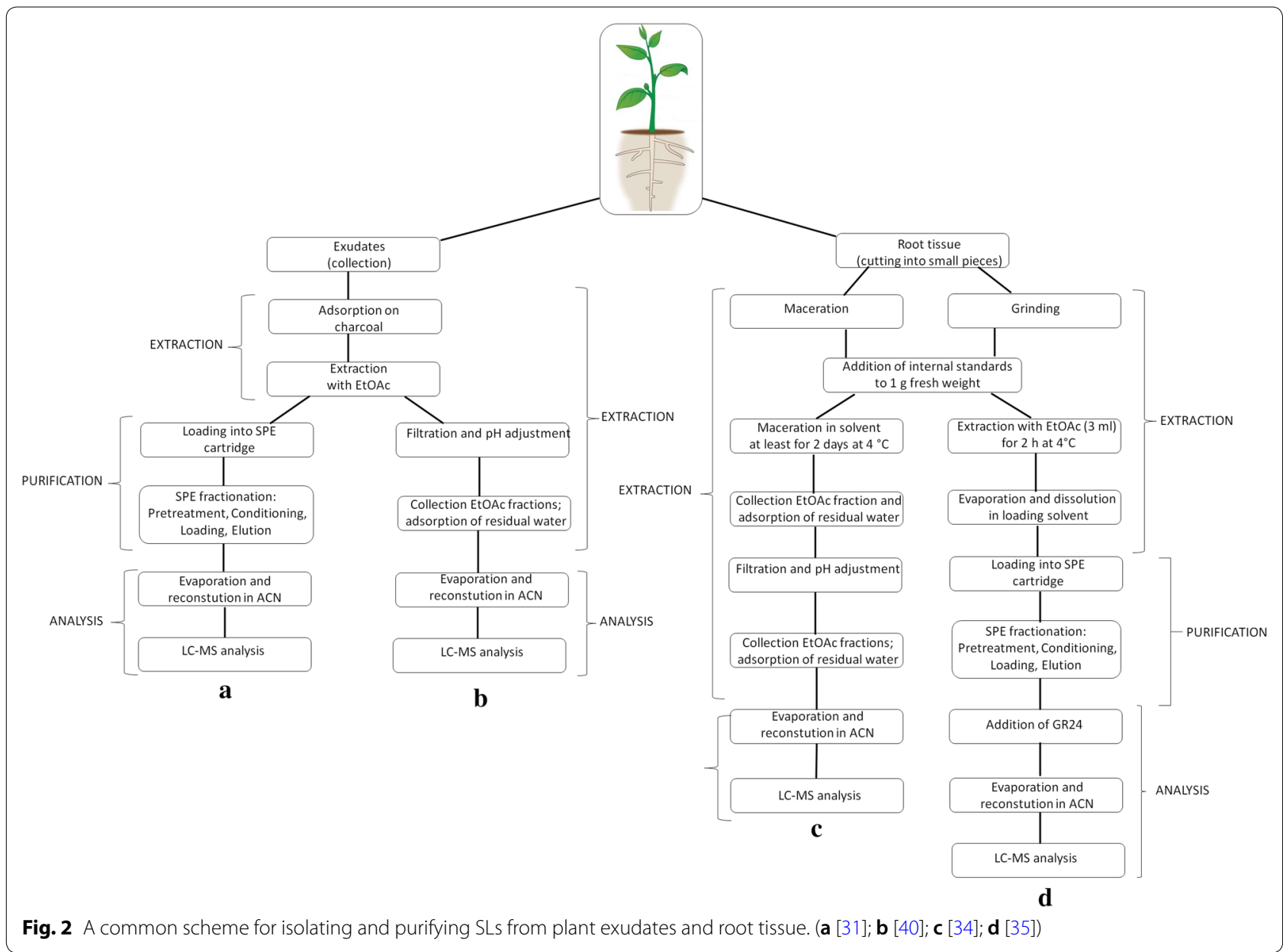

solvent for SLs: 5-deoxystrigol reportedly has a half-life of 1.5 days in $3 \% \mathrm{MeOH}[8,13]$.

\section{Isolation of SLs from root tissues}

The transfer of target analytes from root tissues to organic solvents requires either maceration or extraction of the ground tissue. Maceration involves submerging the intact tissue in freshly distilled solvent for a few days, while extraction involves first homogenizing the plant tissue with a vibration mill or mortar and pestle. To avoid enzymatic or chemical degradation, the tissue must be cooled to $4{ }^{\circ} \mathrm{C}$ during extraction. The efficiency of maceration/extraction depends on the target molecule's polarity and subcellular localisation. Plant hormones are usually associated with other compounds such as phenolics, lipids, and proteins. The extraction solvent must therefore minimize the extraction of interfering substances and not affect the stability or chemical properties of the target compounds [34, 46].

Yoneyama et al. [34] established a standard SL isolation protocol (Fig. 2c) that was successfully applied to sorghum root tissue. This protocol involves macerating small pieces of roots or shoots from 2 to 4 week-old plants in EtOAc. Maceration should not be performed for more than 3 days due to the water content of the plant tissue; water can easily decompose both SLs and EtOAc under slightly acidic conditions. Other measures to prevent potential analyte loss include $\mathrm{pH}$ neutralization, water removal, and omitting nucleophilic substances or solvents $(\mathrm{MeOH})$. EtOAc and acetone are popular solvents for these processes. The final steps are similar to those for isolation from exudates, i.e. washing with $\mathrm{K}_{2} \mathrm{HPO}_{4}$, drying over anhydrous $\mathrm{MgSO}_{4}$ or $\mathrm{Na}_{2} \mathrm{SO}_{4}$, filtration, and evaporation under reduced pressure at temperatures below $35{ }^{\circ} \mathrm{C}$. A very similar isolation protocol was described by López-Ráez et al. [33], who directly analysed EtOAc extracts of tomato tissues [29, 33].

An alternative approach was developed by Boutet-Mercey et al. [35], who combined the extraction of homogenized tissue with purification by SPE (Fig. 2d). Their protocol was tested and optimized for SLs isolated from garden peas (fabacyl acetate, orobanchyl acetate, and 
orobanchol). While other phytohormones are often purified by SPE using hydrophobic C18-type or polymer-type sorbents, silica is commonly used for SLs. This prevents the use of aqueous solvents, which has the additional benefit of improving SL stability and reducing evaporation times [20,35]. Successful quantitative analysis of SLs from tissue samples requires both purification and fractionation. However, fractionation requires the handling of many fractions-more than ten in some cases. To generate these fractions, elution is performed stepwise while varying the composition of the eluent. The elution solvent is typically a mixture of EtOAc with heptane or hexane, in ratios ranging from 100:0 to 0:100 [31]. The optimized SPE protocol of Boutet-Mercey et al. [35] generates only four fractions ( 2 washing and 2 elutions). These authors also reported significant matrix effects for fractions containing higher amounts of EtOAc. A drawback of the SPE procedure is that it increases the total time required for analysis to over $24 \mathrm{~h}$ [29], which is problematic because the instability of SLs means that time is an important factor in their analysis. It is therefore necessary to strike a balance between extraction efficiency and stability. Based on experience and published results, we make the following recommendations for the use of endogenous $\mathrm{SL}$ and synthetic analogues such as GR24 in plant treatments [13, 31-33]:

a. Stock solutions should be prepared using dry inert solvents such as DMF, acetone or acetonitrile, with a maximum storage temperature of $-20^{\circ} \mathrm{C}$;

b. Aqueous solutions containing SLs must be used within $24 \mathrm{~h}$;

c. Methanol is not a suitable solvent for experiments with SLs;

d. EtOAc is a good extraction solvent but must be redistilled before extraction; and

e. Sample preparation (including SPE purification) should be fast and produce an appropriate number of fractions.

\section{Identification and quantification GC-MS}

Gas chromatography (GC) is a very important method in phytohormone analysis, although it is often replaced by liquid chromatography because it requires the derivatization of non-volatile analytes. Nevertheless, Yokota et al. [27] showed that GC is a viable tool for studying SLs by using GC coupled with a mass spectrometer (MS) operating in electron ionization mode (EI) to identify strigol and orobanchol in red clover. They used a non-polar capillary column packed with 5\% (phenyl)

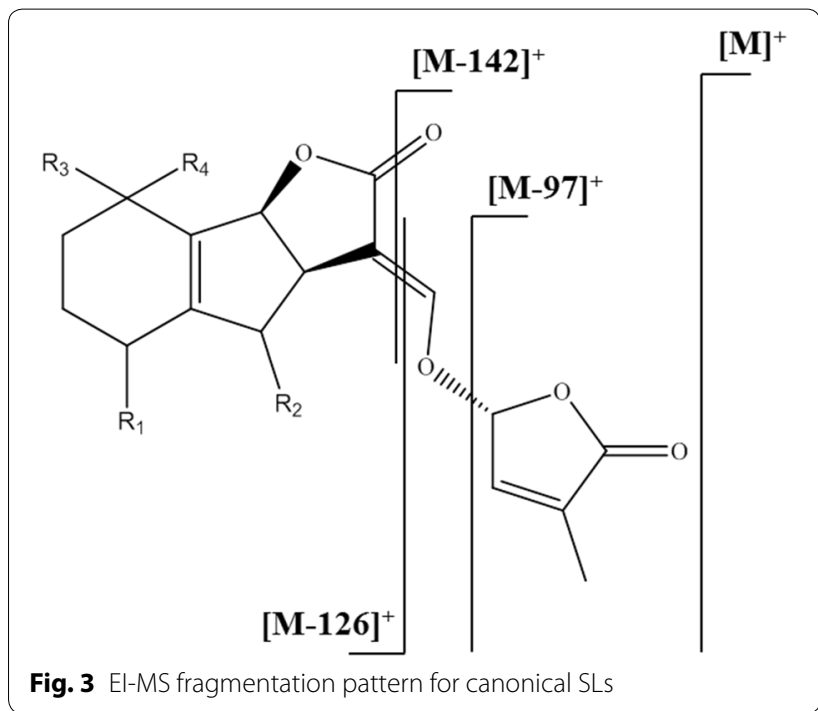

methylpolysiloxane, which was also used by Erickson et al. [47], and Xie et al. [48] (Table 1).

SLs are non-volatile and thermolabile compounds. Their volatility and stability in the injection port of a GC system $\left(150-250{ }^{\circ} \mathrm{C}\right)$ can be improved by derivatization with tetramethylsilane (TMSi), which causes cleavage of the D-ring.

Electron ionization in GC-MS analyzers is always performed at $70 \mathrm{eV}$, which is clearly too high for SLs, causing their molecular peaks to have very low intensities (approximately $4 \%$ of relative abundance). Based on the data summarized by Ćavar et al. [46], we propose that SLs exhibit the fragmentation pattern shown in Fig. 3 when ionized at $70 \mathrm{eV}$ in a GC-EI-MS analyzer. The base peak for all SLs analyzed by GC-EI-MS is $m / z$ 97, which corresponds to the cleaved hydroxymethyl butenolide, i.e. $\mathrm{C}_{5} \mathrm{H}_{5} \mathrm{O}_{2}{ }^{+}$. The peaks corresponding to the $\mathrm{ABC}$ moiety and its fragments formed by cleavage of the enol ether $[\mathrm{M}-126]^{+}$and further cleavage of the oxo-group from the lactone $[\mathrm{M}-142]^{+}$have quite low intensities-at most $15 \%$ of relative abundance.

Since the introduction of HPLC coupled with triple quadrupole $(\mathrm{QqQ})$ mass detectors for identification of SLs by Sato et al. [18], GC has largely served as a supporting method for confirming the spectral characteristics of SLs $[47,49]$.

\section{LC-MS}

The most popular separation method for SLs is high-performance liquid chromatography (HPLC). Separation of SLs is usually performed on a reversed-phase stationary phase with $\mathrm{C} 18$ bonded silica columns. The most common mobile phases are mixtures of neutral or acidified water with methanol or acetonitrile (Table 1). In the early 
Table 2 Overview of $\mathbf{m} / \mathbf{z}$ transitions for known canonical and non-canonical SLs

\begin{tabular}{|c|c|c|c|c|c|c|c|c|}
\hline Strigolactone & {$[\mathrm{M}+\mathrm{H}]^{+}$} & MRM1 & MRM2 & References & {$[\mathrm{M}+\mathrm{Na}]^{+}$} & MRM1 & MRM2 & References \\
\hline Orobanchol & 347 & $347>205$ & $347>97$ & [11] & 369 & $369>272$ & & [82] \\
\hline Orobanchyl acetate & 389 & $389>347$ & $389>233$ & [11 1] & 411 & $411>254$ & $411>239$ & [49] \\
\hline 4-deoxyorobanchol & 331 & $331>216$ & & [52] & & & & \\
\hline 7-oxoorobanchol & & & & & 383 & $383>286$ & & [44] \\
\hline 7-oxoorobanchyl acetate & & & & & 425 & $425>268$ & & {$[44]$} \\
\hline 7a-hydroxyorobanchol & & & & & 385 & $385>288$ & & {$[44]$} \\
\hline 7a-hydroxyorobanchyl acetate & & & & & 427 & $427>270$ & & {$[44]$} \\
\hline 7 $\beta$-hydroxyorobanchol & & & & & 385 & $385>288$ & & {$[44]$} \\
\hline $7 \beta$-hydroxyorobanchyl acetate & & & & & 427 & $427>270$ & & [44] \\
\hline Solanacol & 343 & $343>97$ & $343>183$ & {$[87]$} & 365 & $365>268$ & & [33] \\
\hline Solanacyl acetate & & & & & 407 & $407>250$ & & {$[25]$} \\
\hline Strigol & & & & & 369 & $369>272$ & & {$[18]$} \\
\hline Strigyl acetate & & & & & 411 & $411>254$ & & {$[83]$} \\
\hline Strigone & & & & & 367 & $367>270$ & & {$[31]$} \\
\hline 5-deoxystrigol & 331 & $331>216$ & $331>97$ & {$[88]$} & 353 & $353>256$ & & {$[84]$} \\
\hline Sorgolactone & 317 & $317>97$ & & {$[23]$} & 339 & $339>242$ & & {$[83]$} \\
\hline Sorgomol & & & & & 369 & $369>272$ & & {$[85]$} \\
\hline Fabacyl acetate & 405 & $405>231$ & $405>97$ & [29] & 427 & $427>219$ & $427>242$ & {$[44]$} \\
\hline Fabacol & & & & & 385 & $385>288$ & & {$[44]$} \\
\hline Heliolactone & 361 & $361>233$ & $361>97$ & {$[16]$} & & & & \\
\hline Zealactone & 377 & $377>345$ & $377>97$ & {$[28]$} & & & & \\
\hline Avenaol & 377 & $377>263$ & $377>97$ & {$[89]$} & & & & \\
\hline Carlactone & 303 & $303>97$ & & {$[52]$} & & & & \\
\hline Calactonic acid* & 331 & $331>113$ & & {$[52]$} & & & & \\
\hline Methyl carlactonate & 347 & $347>97$ & & {$[86]$} & & & & \\
\hline Methoxy-5-deoxystrigol & & & & & 383 & $383>286$ & & {$[25]$} \\
\hline
\end{tabular}

${ }^{*}$ Carlactonic acid-precursor ion $[\mathrm{M}-\mathrm{H}]^{-}$

days of SL research, HPLC systems equipped with spectrophotometric detectors (UV or DAD) were used. The usefulness of such systems is limited by their sensitivity and the difficulty of interpreting the UV profiles of SLs-for example, strigol and orobanchol have the same chromophore $[27,50]$. This problem is illustrated by the example of Siame et al. [50], who used UV detection and mistakenly reported that strigol occurred in maize (Zea mays). Two decades later, Jamil et al. [51] disproved this finding and showed that neither strigol nor any other canonical SLs occur in maize. Instead, several noncanonical SLs were detected in maize root exudates [28, $48,51]$.

Traditional HPLC is being replaced by UHPLC (ultrahigh performance liquid chromatography), which offers shorter analysis times and greater separation efficiencies. Routine run-times in UHPLC are typically less than 20 min (Table 1). Quantitation of SLs by UHPLC-MS/ MS (tandem mass spectrometry) is typically performed using the multiple reaction monitoring (MRM) mode $[3,18,52]$. The value of this selective detection mode is demonstrated in a recently published paper by Rial et al. [29], who could not completely separate the isomeric compounds strigol and orobanchol by reversed-phase chromatography but were able to selectively distinguish them by monitoring the relevant MRM transitions.

It should be noted that most SLs are analyzed in positive ion mode but carlactonic acid is analyzed in negative ion mode (Table 2), [52]. Additionally, the choice of MRM transitions depends strongly on mobile phase composition and $\mathrm{pH}$. Acidic conditions suppress formation of sodium or potassium adducts in favor of protonated quasi-molecular ions $\left([\mathrm{M}+\mathrm{H}]^{+}\right)$. However, most authors focus on transitions of sodium adduct ions $[\mathrm{M}+\mathrm{Na}]^{+}$, with the most abundant fragment corresponding to neutral loss of $[\mathrm{M}+\mathrm{Na}-97]^{+}[15,18,30,33-35,44,49,53]$. This transition is monitored because all known SLs have identical D-ring moieties [3]. Table 2 provides an overview of canonical and non-canonical SLs with defined MRM transitions observed in LC-MS/MS experiments. 


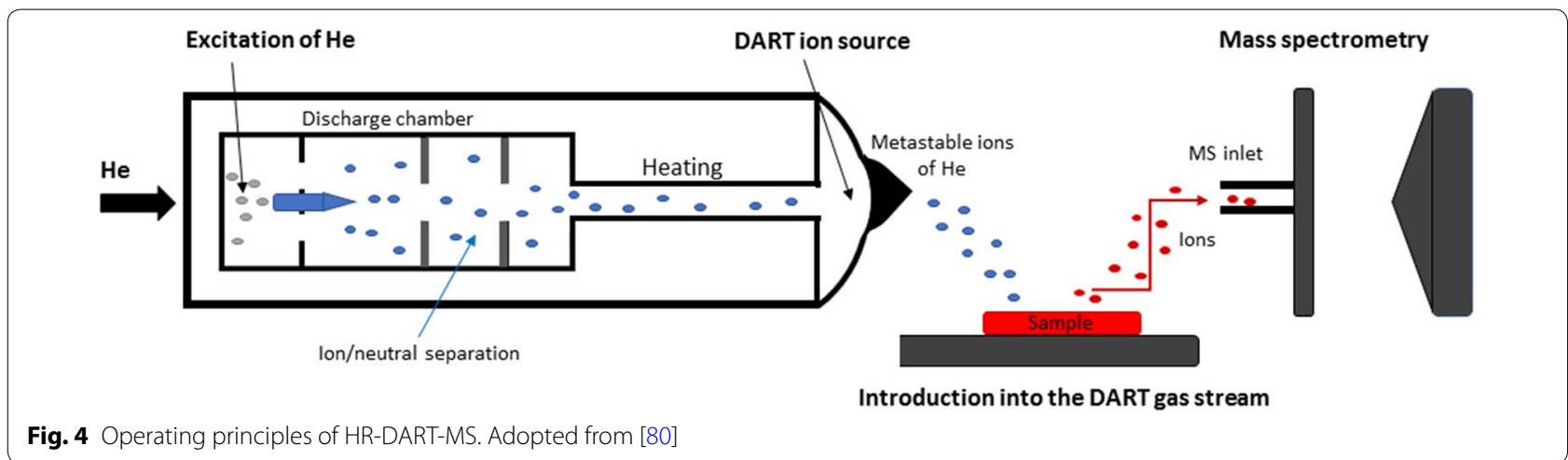

\section{Future tools}

\section{Flash chromatography}

As demonstrated by the above discussion, there is still a need for a general and practical tool for SL isolation. Flash chromatography or extraction using monolithic sorbents could be attractive alternatives to SPE purification. Flash chromatography uses a hybrid medium with small silica gel particles (250-400 mesh size) that necessitate the application of positive pressure to force solvent through the column. Automated flash chromatography systems are multifunction devices that closely resemble HPLC systems: they have gradient pumps, sample injection ports, UV detectors, and inbuilt fraction collectors. They can be used to separate target analytes on scales ranging from a few mg to kilograms, and are much cheaper than preparative HPLC systems [54]. An alternative option is to use monolithic sorbents, whose pore systems enable their use as general tools for isolating SLs and separating their stereoisomers. Some monolithic silica sorbents have additional useful features such as high linear velocities, which increase separation efficiency and thus facilitate the isolation of pure isomers [55].

\section{Nuclear magnetic resonance}

Mass spectrometric techniques are currently indispensable tools for SL detection. A wide range of techniques suitable for diverse applications are available. In recent years, several research groups studying SLs have used a TOF (time of flight) mass analyser together with a tandem mass spectrometry (MS/MS) setup that enables fragmentation of separated compounds and analysis of the resulting ionized fragments $[28,48]$.

An overlooked technique is LC coupled with on-line NMR, which enables real-time detection and detailed characterization of the eluting compounds, including determination of factors such as their stereochemical properties [56]. Unfortunately, its sensitivity and selectivity are much lower than those of MS methods, so it is mainly used for nonselective analysis. The sensitivity of NMR can be improved by using dynamic molecular polarization or cryo- and microprobes [57, 58]. However, even these refinements are insufficient to match the sensitivity and selectivity of MS-based methods, which can detect target analytes in the pmol to fmol range $[59,60]$. On the other hand, NMR offers very high reproducibility and requires minimal sample preparation [57]. It is therefore often used in metabolomic fingerprinting studies that focus on identifying and quantifying compounds associated with drug metabolism and food intake, and for NMR-based metabolomics in phytochemical studies [59-61].

\section{MS ambient techniques}

Other important modern methods are ambient techniques (AT) such as DART (direct analysis in real time) and DESI (desorption electrospray ionization) [62, 63], which can be used to determine the spatial distribution of target compounds in a sample. These relatively new mass spectrometric techniques use an ion source located outside the mass analyser and are suitable for a wide range of low molecular mass compounds. A huge advantage of DART is that it requires minimal or even no sample preparation; small tissue samples or crude extracts can be introduced directly into the ion source [64], (Fig. 4). However, the reproducibility of AT techniques can be limited by problems resulting from outer ionization. AT techniques could potentially serve as the basis of a general fast identification method suitable for detecting SLs in various plant tissues (stems, roots, and leaves). However, many issues remain to be addressed including problems with sample shrinkage (due to losses of water), which changes the nature of the tissue surface [65-68]. Also, each plant organ has a unique structure and thus requires separate process optimization. Coupling DART with HRMS (high resolution mass spectrometry) could make it possible to determine the mass $(\mathrm{m} / \mathrm{z})$ of any compound in a plant tissue sample with relatively high mass accuracy (below $1 \mathrm{ppm}$ ). 


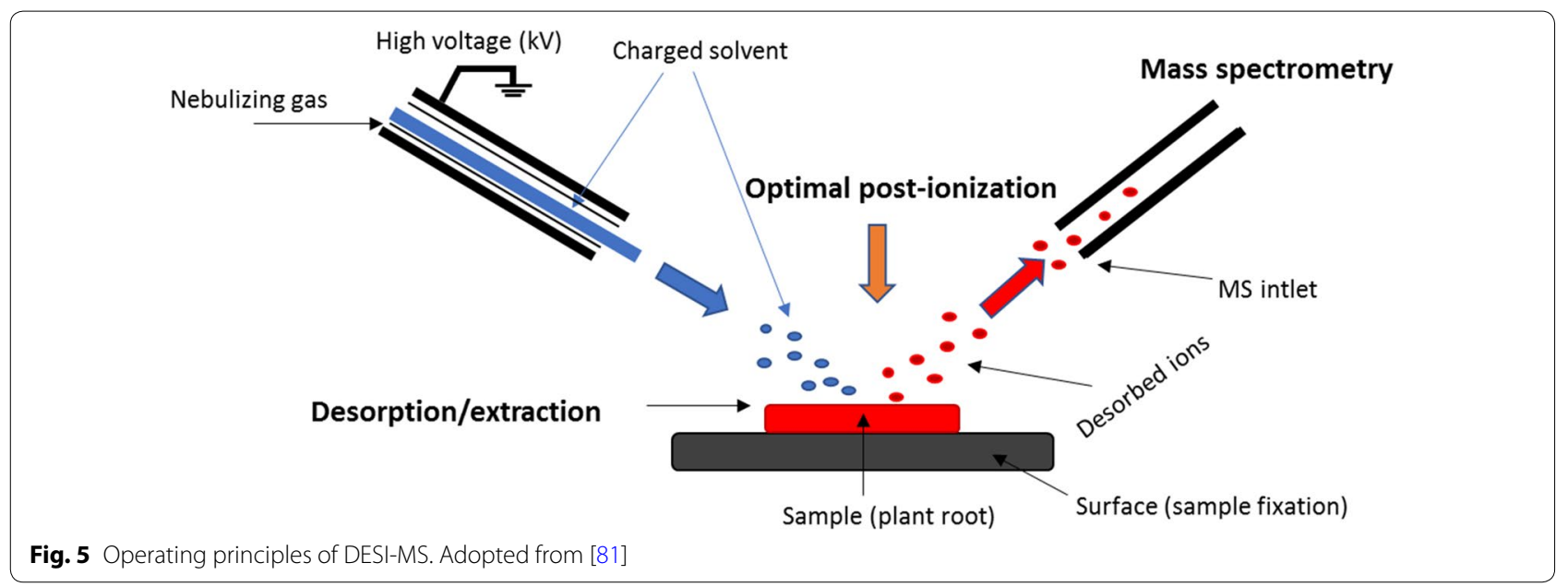

DESI is a mass spectrometry imaging (MSI) technique that provides information about the spatial distribution of target analytes [69] by combining electrospray ionization (ESI) and desorption ionization. It is particularly suitable for low molecular weight compounds such as SLs. The sample to be analysed is fixed or imprinted (Fig. 5) onto the solid surface of a plate, which can be a TLC plate or a plate made from porous Teflon, paper, glass, or plastic [69-71].

The key advantages of MSI (DESI) are that it requires minimal sample manipulation and no separation steps. However, it is very sensitive to matrix effects, which can significantly affect the observed spatial distribution of analytes. In particular, physical properties (roughness on the surface of the analysed sample) can profoundly affect the analysis and the reliability of results obtained using this method [72-74]. Rejšek et al. [74] recently showed that DESI-MS can also be applied to non-planar samples by using an ion source with a laser triangulation system. This upgraded DESI setup obviates the need for chemical pretreatment of samples or sample preparation by imprinting. Moreover, it preserves the native spatial distribution of SLs and other target compounds in the sample.

Another important MSI technique is laser ablation electrospray ionization (LAESI), which was introduced in 2007 [75]. This method also achieves high spatial resolutions (below $1 \mu \mathrm{m}$ ) and has been used to perform quantitative analyses of tissue samples from several plants. For example, it was used to study arginine levels in $A$. cepa bulbs [76]. However, like DESI, it is limited by being much less well-developed than MALDI (matrix-assisted laser desorption/ionization). While DESI and LAESI cannot yet match the resolution achieved with MALDI, they are potentially powerful tools for analysing plant metabolomes and could thus help answer a number of outstanding questions about chemical organization in plants $[68,77,78]$. Plant hormones occur in minute quantities, so that sensitive analytical tools are required for their analyses. The major limitation of MS ambient techniques is their low sensitivity, which could be improved by increasing either the ionization efficiency or the sensitivity of ion detection. To assess the potential of DARTand DESI-MS we are currently finalizing a method paper that discusses this issue.

\section{Conclusions}

Chemical analysis is central to research on the biochemistry of SLs and their roles in plant development and physiology. Before performing any such analysis, it is essential to know at least the main chemical properties of the target analytes, such as their structures, stability under certain conditions, and chemical reactivity, as well as the levels at which they exist in the tissues of interest. This review summarized the different methods that have been used to isolate and purify SLs from root tissues and exudates, and to identify the SLs present in the resulting isolates. The advantages and drawbacks of each method have been highlighted, which should be valuable information for plant scientists seeking to study these phytohormones. Additionally, we have presented guidelines for protocol selection that should help minimize losses during isolation and purification prior to final analysis.

Qualitative and especially quantitative analyses of SLs are needed to clarify their roles in regulating plant development and their interactions with other phytohormones. Of the techniques available for this purpose, LC-MS/MS continues to be the most generally useful and widely used [79]. However, more recently developed highly sensitive analytical methods such as HR-DARTMS and HR-DESI-MS can provide information that 
cannot be obtained using LC-MS/MS, such as data on the spatial distribution of target analytes. As such, they could be valuable complementary tools for semi-quantitative analysis of SLs. Additionally, these methods require little or no sample preparation, enabling rapid analysis with minimal risk of analyte degradation.

\section{Acknowledgements}

This work was supported by institutional support MZE-RO0418. PT was supported also from ERDF project "Plants as a tool for sustainable global development" (No. CZ.02.1.01/0.0/0.0/16_019/0000827). BK was supported from CEITEC 2020 (LQ1601) with additional financial support from the Ministry of Education, Youth and Sports of the Czech Republic under the National Sustainability Programme II. The authors are grateful to Sees-editing Ltd. (UK) and Prof. Peter Hedden for editing the manuscript.

\section{Authors' contributions}

$\mathrm{RH}$ and PT proposed the idea of the manuscript and wrote the outline. All authors wrote the manuscript. All authors read and approved the final manuscript.

\section{Funding}

This work was supported by institutional support MZE-RO0418. PT was supported also from ERDF project "Plants as a tool for sustainable global development" (No. CZ.02.1.01/0.0/0.0/16_019/0000827). BK was supported from CEITEC 2020 (LQ1601) with additional financial support from the Ministry of Education, Youth and Sports of the Czech Republic under the National Sustainability Programme II.

\section{Availability of data and materials \\ Not applicable}

\section{Ethics approval and consent to participate}

Not applicable.

\section{Consent for publication}

Not applicable.

\section{Competing interests}

The authors declared that they have no competing interests.

\section{Author details}

${ }^{1}$ Centre of Region Haná for Biotechnological and Agricultural Research, Department of Phytochemistry, Faculty of Science, Palacky University, Šlechtitelů 27, 78371 Olomouc, Czechia. ${ }^{2}$ Centre of Region Haná for Biotechnological and Agricultural Research, Department of Genetic Resources for Vegetables, Medicinal and Special Plants, Crop Research Institute, Šlechtitelů 29, 78371 Olomouc, Czechia. ${ }^{3}$ Central European Institute of Technology, Mendel University in Brno, Zemědělská 1, 61300 Brno, Czechia. ${ }^{4}$ Department of Chemistry and Biochemistry, Mendel University in Brno, Zemědělská 1, 613 00 Brno, Czechia.

Received: 30 March 2020 Accepted: 15 May 2020

Published online: 29 May 2020

\section{References}

1. Matusova R, Rani K, Verstappen FWA, Franssen MCR, Beale MH, Bouwmeester HJ. The strigolactone germination stimulants of the plant-parasitic Striga and Orobanche spp. are derived from the carotenoid pathway. Plant Physiol. 2005;139:920-34.

2. Cook CE, Whichard LP, Turner B, Wall ME, Egley GH. Germination of witchweed (Striga lutea Lour.): isolation and properties of a potent stimulant. Science. 1966:154:1189-90.

3. Xie X, Yoneyama K, Yoneyama K. The strigolactone story. Ann Rev Phytopatol. 2010;48:93-117.
4. Nomura S, Nakashima H, Mizutani M, Takikawa H, Sugimoto Y. Structural requirements of strigolactones for germination induction and inhibition of Striga gesnerioides seeds. Plant Cell Rep. 2013;32:829-38.

5. Proust H, Hoffmann B, Xie XN, Yoneyama K, Schaefer DG, Yoneyama K, Nogue F, Rameau C. Strigolactones regulate protonema branching and act as a quorum sensing like signal in the moss Physcomitrella patens. Development. 2011;138:1531-9.

6. Cook CE, Whichard LP, Wall ME, Egley GH, Coggon P, Luhan PA, McPhail AT. Germination stimulants. II. The structure of strigol-a potent seed germination stimulant for witchweed (Striga lutea Lour.). J Amer Chem Soc. 1972;94:6198-9.

7. Al-Babili S, Bouwmeester HJ. Strigolactones, a novel carotenoidderived plant hormone. Ann Rev Plant Biol. 2015;66:161-6.

8. Akiyama K, Matsuzaki K, Hayashi H. Plant sesquiterpenes induce hyphal branching in arbuscular mycorrhizal fungi. Nature. 2005;435:824-7.

9. Zhang $Y$, van Dijk AD, Scaffidi A, Flematti GR, Hofmann M, Charnikhova T, Verstappen F, Hepworth J, van der Krol S, Leyser O, Smith SM, Zwanenburg B, Al-Babili S, Ruyter-Spira C, Bouwmeester HJ. Rice cytochrome P450 MAX1 homologs catalyze distinct steps in strigolactone biosynthesis. Nat Chem Biol. 2014;10:1028-33.

10. Joel DM. The long-term approach to parasitic weeds control: manipulation of specific developmental mechanisms of the parasite. Crop Prot. 2000;19:753-8.

11. Kohlen W, Charnikhova T, Liu Q, Bours R, Domagalska MA, Beguerie S, Verstappen F, Leyser O, Bouwmeester H, Ruyter-Spira C. Strigolactones are transported through the xylem and play a key role in shoot architectural response to phosphate deficiency in nonarbuscular mycorrhizal host Arabidopsis. Plant Physiol. 2011;155:974-87.

12. Xie X. Structural diversity of strigolactones and their distribution in the plant kingdom. Pest Sci. 2016;41:175-80.

13. Halouzka R, Tarkowski P, Zwanenburg B, Ćavar Zeljković S. Stability of strigolactone analog GR24 toward nucleophiles. Pest Manag Sci. 2018;74:896-904

14. Zwanenburg B, Pospíšil T. Structure and activity of strigolactones: new plant hormones with a rich future. Mol Plant. 2013;6:38-62.

15. Yoneyama K, Xie X, Sekimoto H, Takeuchi Y, Ogasawara S, Akiyama K, Hayashi H, Yoneyama K. Strigolactones, host recognition signals for root parasitic plants and arbuscular mycorrhizal fungi, from Fabaceae plants. New Phytol. 2008;179:484-94.

16. Ueno K, Furumoto T, Umeda S, Mizutani M, Takikawa H, Batchvarova R, Sugimoto Y. Heliolactone, a non-sesquiterpene lactone germination stimulant for root parasitic weeds from sunflower. Phytochemistry. 2014; 108:122-8

17. Xie X, Mori N, Yoneyama K, Nomura T, Uchida K, Yoneyama K, Akiyama K. Lotuslactone, a non-canonical strigolactone from Lotus japonicus. Phytochemistry. 2019;157:200-5.

18. Sato D, Awad AA, Chae SH, Yokota T, Sugimoto Y, Takeuchi Y, Yoneyama K. Analysis of strigolactones, germination stimulants for Striga and Orobanche, by high-performance liquid chromatography/tandem mass spectrometry. J Agric Food Chem. 2003;51:1162-8.

19. Podlešáková K, Tarkowská D, Pěnčík A, Oklešťková J, Turečková V, Floková K, Tarkowski P. Nové trendy v analýze fytohormonů. Chem Listy. 2012;106:373-9.

20. Tarkowká D, Novák O, Floková K, Turečková V, Grúz J, Rolčík J, Strnad M. Quo vadis plant hormone analysis? Planta. 2014;240:55-76.

21. Novák O, Tarkowski P, Tarkowská D, Doležal K, Lenobel R, Strnad M. Quantitative analysis of cytokinins in plants by liquid chromatography-single-quadrupole mass spectrometry. Anal Chim Acta. 2003:480:207-18.

22. Tarkowski P, Ge L, Yong JWH, Tan SN. Analytical methods for cytokinins. Trend Anal Chem. 2009;28:323-35.

23. Delaux PM, Xie XN, Timme RE, Puech-Pages V, Dunand C, Lecompte E, Delwiche CF, Yoneyama K, Becard G, Sejalon-Delmas N. Origin of strigolactones in the green lineage. New Phytol. 2012;195:857-71.

24. Cardoso C, Ruyter-Spira C, Bouwmeester HJ. Strigolactones and root infestation by plant-parasitic Striga, Orobanche and Phelipanche spp. Plant Sci. 2011;180:414-20.

25. Xie X, Yoneyama K, Kisugi T, Uchida K, Ito S, Akiyama K, Hayashi $\mathrm{H}$, Yokota T, Nomura T, Yoneyama K. Confirming stereochemical structures of strigolactones produced by rice and tobacco. Mol Plant. 2013:6:153-63. 
26. Šimura J, Antoniadi I, Široká J, Tarkowska D, Strnad M, Ljung K, Novák O. Plant Hormonomics: multiple phytohormone profiling by targeted metabolomics. Plant Phys. 2018;177:476-89.

27. Yokota T, Sakai H, Okuno K, Yoneyama K, Takeuchi Y. Alectrol and orobanchol, germination stimulants for Orobanche minor, from its host red clover. Phytochemistry. 1998:49:1967-73.

28. Charnikhova TV, Gaus K, Lumbroso A, Sanders M, Vincken JP, De Mesmaeker A, Ruyter-Spira CP, Screpanti C, Bouwmeester HJ. Zealactones. Novel natural strigolactones from maize. Phytochemistry. 2017;137:123-31.

29. Rial C, Varela RM, Molinillo JMG, López-Ráez JA, Macías FA. A new UPLCMS/MS method for the direct determination of strigolactones in root exudates and extracts. Phytochem Anal. 2018;30:110-6.

30. Awad AA, Sato D, Kusumoto D, Kamioka H, Takeuchi Y, Yoneyama K. Characterization of strigolactones for the root parasitic plants Striga and Orobanche, produced by maize, millet and sorghum. Plant Growth Regul. 2006:48:221-7.

31. Kisugi T, Xie XN, Kim HI, Yoneyama K, Sado A, Akiyama K, Hayashi H, Uchida K, Yokota T, Nomura T, Yoneyama K. Strigone, isolation and identification as a natural strigolactone from Houttuynia cordata. Phytochemistry. 2013;87:60-4.

32. Yoneyama K, Arakawa R, Ishimoto K, Kim HI, Kisugi T, Xie X, Nomura T, Kanampiu F, Yokota T, Ezawa T, Yoneyama K. Difference in Striga-susceptibility is reflected in strigolactone secretion profile, but not in compatibility and host preference in arbuscular mycorrhizal symbiosis in two maize cultivars. New Phytol. 2015;206:983-9.

33. López-Ráez JA, Charnikhova T, Gómez-Roldán V, Matusova R, Kohlen W, De Vos R, Verstappen F, Puech-Pages V, Bécard G, Mulder P, Bouwmeester $\mathrm{H}$. Tomato strigolactones are derived from carotenoids and their biosynthesis is promoted by phosphate starvation. New Phytol. 2008:178:863-74.

34. Yoneyama K, Xie X, Nomura T, Yoneyama K. Extraction and measurement of strigolactones in sorghum roots. Bio-protocol. 2016;2016(6):e1763.

35. Boutet-Mercey S, Perreau F, Roux A, Clavé G, Pillot JP, Schmitz-Afonso I, Touboul D, Mouille G, Rameau C, Boyer FD. Validated method for strigolactone quantification by ultra high-performance liquid chromatography-electrospray ionisation tandem mass spectrometry using novel deuterium labelled standards. Phytochem Anal. 2018;29:59-68.

36. Walker TS, Bais HP, Grotewold E, Vivanco JM. Root exudation and rhizosphere biology. Plant Physiol. 2003;132:44-51.

37. Merbach W, Mirus E, Knof G, Remus R, Ruppel S, Russow R, Gransee A, Schulze J. Release of carbon and nitrogen compounds by plant roots and their possible ecological importance. J Plant Nutr Soil Sci. 1999;162:373-83.

38. Bagger CL, Sørensen H, Sørensen JC. High-quality oils, proteins, and bioactive products for food and non-food purposes based on biorefining of cruciferous oilseed crops. In: Gueguen J, Popineau Y, editors. Plant proteins from European crops. Berlin: Springer; 1998. p. 272-8.

39. Cai Z, Kastell A, Knorr D, Smetanska I. Exudation: an expanding technique for continuous production and release of secondary metabolites from plant cell suspension and hairy root culture. Plant Cell Rep. 2012;31:461-77.

40. Yoneyama K, Yoneyama K, Takeuchi Y, Sekimoto H. Phosphorus deficiency in red clover promotes exudation of orobanchol, the signal for mycorrhizal symbionts and germination stimulant for root parasites. Planta. 2007;225:1031-8.

41. Yoneyama $K$, Xie $X$, Kusumoto D, Sekimoto $H$, Sugimoto $Y$, Takeuchi $Y$, Yoneyama K Nitrogen deficiency as well as phosphorus deficiency in sorghum promotes the production and exudation of 5-deoxystrigol, the host recognition signal for arbuscular mycorrhizal fungi and root parasites. Planta. 2007;227:125-32.

42. Jamil M, Charnikhova T, Cardoso C, Jamil T, Ueno K, Verstappen F, Asami T, Bouwmeester HJ. Quantification of the relationship between strigolactones and Striga hermonthica infection in rice under varying levels of nitrogen and phosphorus. Weed Res. 2011;51:373-85.

43. Yoneyama K, Xie X, Kisugi T, Nomura T, Yoneyama K. Nitrogen and phosphorus fertilization negatively affects strigolactone production and exudation in sorghum. Planta. 2013;238:885-94.

44. Yoneyama K, Xie X, Kisugi T, Nomura T, Sekimoto H, Yokota T, Yoneyama K. Characterization of strigolactones exuded by Asteraceae plants. Plant Growth Regul. 2011;65:495-504.
45. Foo E, Yoneyama K, Hugill CJ, Quittenden LJ, Reid JB. Strigolactones and the regulation of pea symbioses in response to nitrate and phosphate deficiency. Mol Plant. 2013;6:76-87.

46. Ćavar S, Zwanenburg B, Tarkowski P. Strigolactones: occurrence, structure and biological activity in the rhizosphere. Phytochem Rev. 2015;14:691-711.

47. Erickson J, Schott D, Reverri T, Muhsin W, Ruttledge T. GC-MS Analysis of hydrophobic root exudates of Sorghum and implications on the parasitic plant Striga asiatica. J Agric Food Chem. 2001;49:5537-42.

48. Xie X, Kisugi T, Yoneyama K, Nomura T, Akiyama K, Uchida K, Yokota T, McErlean CSP, Yoneyama K. Methyl zealactonoate, a novel germination stimulant for root parasitic weeds produced by maize. J Pestic Sci. 2017:42:58-61.

49. Xie X, Yoneyama K, Kusumoto D, Yamada Y, Yokota T, Takeuchi Y, Yoneyama K. Isolation and identification of alectrol as (+)-orobanchyl acetate, a novel germination stimulant for root parasitic plants. Phytochemistry. 2008;69:427-31.

50. Siame BA, Weerasuriya Y, Wood K, Ejeta G, Butler LG. Isolation of strigol, a germination stimulant for Striga asiatica, from host plants. J Agri Food Chem. 1993:41:1486-91.

51. Jamil M, Kanampiu FK, Karaya H, Charnikhova T, Bouwmeester HJ. Striga hermonthica parasitism in maize in response to $\mathrm{N}$ and $\mathrm{P}$ fertilisers. Field Crops Res. 2012;134:1-10.

52. Iseki M, Shida K, Kuwabara K, Wakabayashi T, Mizutani M, Takikawa H, Sugimoto Y. Evidence for species-dependent biosynthetic pathways for converting carlactone to strigolactones in plants. J Exp Bot. 2018;69:2305-18.

53. López-Ráez JA, Kohlen W, Charnikhova T, Mulder P, Undas AK, Sergeant MJ, Verstappen F, Bugg TDH, Thompson AJ, Ruyter-Spira C, Bouwmeester H. Does abscisic acid affect strigolactone biosynthesis? New Phytol. 2010;187:343-54.

54. Ayare P, Khanvilkar V, Chalak N. Flash Chromatography: area \& Applications. Pharma Tutor. 2014;2:89-103.

55. Schulte M, Dingenen J. Monolithic silica sorbents for separation of diastereomers by means of simulated moving bed chromatography. J Chomatogr A. 2001:923:17-25.

56. Lindon JC, Bailey NJC, Nicholson JK, Wilson ID. Biomedical applications of directly-coupled chromatography-nuclear magnetic resonance (NMR) spectroscopy and mass spectrometry (MS). In: Wilson D, editor. Handbook of analytical separations, vol. 4. Amsterdam: Elsevier; 2003. p. 293-329.

57. Emwas AMS, Salek RM, Griffi JL, Merzaban J. NMR-based metabolomics in human disease diagnosis: applications, limitations, and recommendations. Metabolomics. 2013;9:1048-72.

58. Emwas AHMS. The strengths and weaknesses of nmr spectroscopy and mass spectrometry with particular focus on metabolomics research. Method Mol Biol. 2015;1277:161-93.

59. Sumner LW, Mendes P, Dixon RA. Plant metabolomics: large-scale phytochemistry in the functional genomics era. Phytochemistry. 2003;62:817-36.

60. Bedair M. Sumner LW Current and emerging mass-spectrometry technologies for metabolomics. Trac-Trend Anal Chem. 2008;27:238-50.

61. Verpoorte R, Choi YH, Kim HK. NMR-based metabolomics at work in phytochemistry. Phytochem Rev. 2007:6:3-14.

62. Venter A, Nefliu M, Cooks RG. Ambient desorption mass spectrometry. Trac Trend Anal Chem. 2008:27:284-90.

63. Weston DJ. Ambient ionization mass spectrometry: current understanding of mechanistic theory; analytical performance and application areas. Analyst. 2010;135:661-8.

64. Gross JH. Direct analysis in real time-a critical review on DART-MS. Anal Bioanal Chem. 2014;406:63-80.

65. Cha S, Zhang H, Ilarsla HI, Wurtele ES, Brachova L, Nikolau BJ, Yeung ES. Direct profiling and imaging of plant metabolites in intact tissues by using colloidal graphite-assisted laser desorption ionization mass spectrometry. Plant J. 2008:55:348-60.

66. Nemes P, Barton AA, Vertes A. Three-dimensional imaging of metabolites in tissues under ambient conditions by laser ablation electrospray ionization mass spectrometry. Anal Chem. 2009;81:6668-75.

67. Navare AT, Mayoral JG, Nouzova M, Noriega FG, Fernández FM. Rapid direct analysis in real time (DART) mass spectrometric detection of juvenile hormone III and its terpene precursors. Anal Bioanal Chem. 2010;398:3005-13. 
68. Dong Y, Lin B, Malitsky B, Rogachev I, Aharoni A, Kaftan F, Svatoš A, Franceschi P. Sample preparation for mass spectrometry imaging of plant tissues: a review. Front Plant Sci. 2016;7(60):1-16.

69. Thunig J, Hansen SH, Janfelt C. Analysis of secondary plant metabolites by indirect desorption electrospray ionization imaging mass spectrometry. Anal Chem. 2011;83:3256-9.

70. Venter A, Sojka PE, Cooks RG. Droplet dynamics and ionization mechanisms in desorption electrospray ionization mass spectrometry. Anal Chem. 2006:78:8549-55.

71. Ifa D, Srimany A, Eberlin LS, Naik HR, Bhat V, Cooks RG, Thalappil P. Tissue imprint imaging by desorption electrospray ionization mass spectrometry. Anal Method. 2011;3:1910-2.

72. Takats Z, Wiseman JM, Cooks RG. Ambient mass spectrometry using desorption electrospray ionization (DESI): instrumentation, mechanisms and applications in forensics, chemistry, and biology. J Mass Spectrom. 2005:40:1261-75.

73. Ifa DR, Manicke NE, Rusine AL, Cooks RG. Quantitative analysis of small molecules by desorption electrospray ionization mass spectrometry from polytetrafluoroethylene surfaces. Rapid Commun Mass Spectrom. 2008:22:503-10

74. Rejšek J, Vrkoslav V, Pokorný V, Přibyl V, Cvačka J. Ion source with laser triangulation for ambient mass spectrometry of nonplanar samples. Anal Chem. 2017;89:11452-9.

75. Nemes $P$, Vertes A. Laser ablation electrospray ionization for atmospheric pressure, in vivo, and imaging mass spectrometry. Anal Chem. 2007;79:8098-106.

76. Shrestha B, Patt JM, Vertes A. In situ cell-by-cell imaging and analysis of small cell populations by mass spectrometry. Anal Chem. 2011;83:2947-55

77. Shroff R, Schramm K, Jeschke V, Nemes P, Vertes A, Gershenzon J, Svatoš A. Quantification of plant surface metabolites by matrix-assisted laser desorption-ionization mass spectrometry imaging: glucosinolates on Arabidopsis thaliana leaves. Plant J. 2015:81:961-72.

78. Bartels B, Svatoš A. Spatially resolved in vivo plant metabolomics by laser ablation-based mass spectrometry imaging (MSI) techniques: LDI-MSI and LAESI. Front Plant Sci. 2015;6:471.

79. Wang L, Zou Y, Kaw HY, Wang G, Sun H, Cai L, Li C, Meng L-Y, Li D. Recent developments and emerging trends of mass spectrometric methods in plant hormone analysis: a review. Plant Methods. 2020;16:54.

80. Cody RB, Laramée JA, Durst HD. Versatile new ion source for the analysis of materials in open air under ambient conditions. Anal Chem. 2005;77:2297-302.
81. Hiraoka K, Mori K, Asakawa D. Fundamental aspects of electrospray droplet impact/SIMS. J Mass Spectrom. 2006;41:894-902.

82. Xie X, Yoneyama K, Kurita J-Y, Harada Y, Yamada Y, Takeuchi Y. 7-Oxoorobanchyl acetate and 7-oxoorobanchol as germination stimulants for root parasitic plants from flax (Linum usitatissimum). Biosci Biotechnol Biochem. 2009;73:1367-70.

83. Sato D, Awad AA, Takeuchi Y, Yoneyama K. Confirmation and quantification of strigolactones, germination stimulants for root parasitic plants Striga and Orobanche, produced by cotton. Biosci Biotechnol Biochem. 2005;69:98-102.

84. Xie X, Kusumoto D, Takeuchi Y, Yoneyama K, Yamada Y, Yoneyama K. 2'-Epi-orobanchol and solanacol, two unique strigolactones, germination stimulants for root parasitic weeds, produced by tobacco. J Agric Food Chem. 2007;55:8067-72.

85. Yoneyama K, Awad AA, Xie X, Yoneyama K, Takeuchi Y. Strigolactones as germination stimulants for root parasitic plants. Plant Cell Physiol. 2010;51:1095-103.

86. Abe S, Sado A, Tanaka K, Kisugi T, Asami K, Ota S, Kim HI, Yoneyama K, Xie X, Ohnishi T, Seto Y, Yamaguchi S, Akiyama K, Yoneyama K, Nomura T. Carlactone is converted to carlactonoic acid by MAX 1 in Arabidopsis and its methyl ester can directly interact with AtD14 in vitro. Proc Nat Acad Sci USA. 2014;111:18084-9.

87. López-Ráez JA, Charnikova T, Mulder P, Kohlen W, Bino R, Levin I, Bouwmeester $\mathrm{H}$. Susceptibility of the tomato mutant high pigment-2dg (hp2dg) to Orobanche spp. infection. J Agric Food Chem. 2008;56:6326-32.

88. Umehara M, Hanada A, Yoshida S, Akiyama K, Arite T, Takeda-Kamiya N, Magome H, Kamiya Y, Shirasu K, Yoneyama K, Kyozuka J, Yamaguchi S. Inhibition of shoot branching by new terpenoid plant hormones. Nature. 2008;455:195-200.

89. Kim HI, Kisugi T, Khetkam P, Xie X, Yoneyama K, Uchida K, Yokota T, Nomura T, McErlean CSP, Yoneyama K. Avenaol, a germination stimulant for root parasitic plants from Avena strigosa. Phytochemistry. 2014;103:85-8.

\section{Publisher's Note}

Springer Nature remains neutral with regard to jurisdictional claims in published maps and institutional affiliations.
Ready to submit your research? Choose BMC and benefit from:

- fast, convenient online submission

- thorough peer review by experienced researchers in your field

- rapid publication on acceptance

- support for research data, including large and complex data types

- gold Open Access which fosters wider collaboration and increased citations

- maximum visibility for your research: over $100 \mathrm{M}$ website views per year

At BMC, research is always in progress.

Learn more biomedcentral.com/submissions 